\title{
Assessment of Factors Associated with Low Adherence to Pharmacotherapy in Elderly Patients
}

\author{
Naveen Thekkemelathil Roy', Manjusha Sajith', Madhu Pankaj Bansode ${ }^{2}$ \\ 'Department of Clinical Pharmacy, Bharati Vidyapeeth Deemed University, Poona College of Pharmacy, Pune, Maharashtra, INDIA \\ 2Department of General Medicine, Bharati Hospital and Research centre, Pune, Maharashtra, INDIA.
}

\begin{abstract}
Objective: To assess factors associated with low adherence to pharmacotherapy in elderly patients. Methods: A prospective cross sectional observational study was conducted in Bharati Hospital and Research Centre, Pune over a period of 6 months. A total of 240 Elderly patients ( $\geq 60$ years), taking 4 or more medications daily for any medical illness or illnesses were enrolled in the study. The details like age, gender, educational and employment status, physical activity, social history, past medical and medication history, current medications were noted in self pre designed patient pro forma. The medication adherence was assessed by using Brief Medication Questionnaire (BMQ). Results: The assessment of the patient's responses to the four scale BMO showed that out of 240 patients, only $5.8 \%$ patients were adherent in regimen scale, $60 \%$ were adherent in belief scale, $15 \%$ were adherent in recall scale and $37.5 \%$ were adherent in access scale. Complexity of medication regimen $(74.1 \%)$ was the main barrier to medication adherence. More than half of patients were unable to name their medications (68.3\%). The main reason for non adherence would be related to patient related factors such as lack of knowledge about the disease $(63.3 \%)$, inadequate knowledge regarding therapy (60\%), taking so many pills at the same time $(51.7 \%)$, forgetfulness $(50.84 \%)$, difficulty in remembering to take all the pills (48.3\%) and difficulty on refilling in time
\end{abstract}

(20.0\%). Conclusion: Various factors associated with medication nonadherence were complexity of medication regimen, lack of knowledge about the disease and therapy, difficulty in remembering to take medications and taking so many pills at the same time.

Key words: Brief medication questionnaire, Factors associated with medication non-adherence.

Key message: Adherence to prescribed medication regimens is difficult for all patients and particularly challenging for the elderly. This is because non-adherence is less easily detected and harder to resolve in elderly than in younger people. Therefore the purpose of our study was to identify the factors related to low adherence to medications in elderly patients.

\section{Correspondence :}

Mrs. Manjusha Sajith, Poona College of Pharmacy, Bharati Vidyapeeth Deemed University, Pune, Maharashtra.

Phone no: 9730080959

Email: manjusaji1@yahoo.com

DOI: 10.5530/jyp.2017.9.53

\section{INTRODUCTION}

Medication use is ubiquitous among elderly people. According to surveys, $90 \%$ of elderly use one or more prescription medications per week, $41 \%$ of older adults take five or more medications and $12 \%$ use 10 or more medications per week. ${ }^{1}$

Adherence is a multifactorial phenomenon and varies from population to population. Factors such as age, gender, socioeconomic status and level of disease severity, complexity of prescribed medications, social acceptance, pooor patient related relationships, cost, forgetfulness and presence of psychological problems have all been shown to affect the adherence in various populations. ${ }^{2}$ Medication nonadherence is the multifaceted problem, responsible for increasing the important medical and public health issues like worsened therapeutic outcome, higher hospitalization rates, and increased health care costs. ${ }^{3}$ It is common for elderly people to be treated for different health conditions simultaneously, and this can result in a complex medication regime. As well as presenting pharmacological risks, poly pharmacy, defined as simultaneous and chronic use of multiple medications, predisposes those practicing it to low adherence.

Many factors may influence medication compliance in elderly population, including unclear instructions, inadequate patient education, lack of patient involvement in the treatment plan, medication cost, side effects and the complexity of the dosing regimen. Many studies have shown that most of the elderly people do not take their medications at the right time or in the right amount because of complicating factors such as the number of medications prescribed and the number of providers seen for multiple health problems, as well as other physical and cognitive challenges the elderly face. Lack of knowledge of their illnesses and the role medicines play in their long-term management can lead to intentional medication non-adherence.

Strong evidence shows that elderly patients with chronic illnesses have difficulty adhering to their recommended medication regimen. To improve medication adherence, the multi-factorial causes of decreased adherence must be understood. The multifactorial nature of poor medication adherence implies that only a sustained, coordinated effort will ensure optimal medication adherence and realization of the full benefits of current therapies. Therefore the purpose of our study is to identify the factors related to low adherence to medications in elderly patients.

\section{METHODS AND MATERIALS}

A prospective cross sectional observational study was conducted in Outpatient clinic of Bharati Hospital and Research Centre, Pune over a period of 6 months to assess factors associated with low adherence to pharmacotherapy in elderly patients. A total of 240 Elderly patients ( $\geq 60$ years), taking 4 or more chronic medications daily for any medical illness were enrolled in the study. Elderly Patients with assisted living or nursing home residents and those with terminal medical conditions were excluded from the study. Ethical approval was obtained for the 


\begin{tabular}{|c|c|c|}
\hline \multicolumn{2}{|l|}{ Screen } & Scoring \\
\hline \multicolumn{3}{|l|}{ Regimen Screen } \\
\hline \multicolumn{2}{|l|}{ Did R fail to list the prescribed drug in the initial (spontaneous) report? } & $1=$ yes $\quad 0=$ no \\
\hline \multicolumn{2}{|l|}{ Did R stop or interrupt therapy due to a late refill or other reason? } & $1=$ yes $0=$ no \\
\hline \multicolumn{2}{|l|}{ Did R report any missed days or doses? } & $1=$ yes $\quad 0=$ no \\
\hline \multicolumn{2}{|l|}{ Did $\mathrm{R}$ reduce or cut down the prescribed amount per dose? } & $1=$ yes $\quad 0=$ no \\
\hline \multicolumn{2}{|l|}{ Did R take any extra doses or more medication than prescribed? } & $1=$ yes $\quad 0=$ no \\
\hline \multicolumn{2}{|l|}{ Did R report "don’t know" in response to any questions? } & $1=$ yes $0=$ no \\
\hline \multicolumn{2}{|l|}{ Did R refuse to answer any questions? } & $1=$ yes $\quad 0=$ no \\
\hline \multicolumn{3}{|l|}{ Belief Screen } \\
\hline \multicolumn{2}{|c|}{ Did R report "not well" or "don't know" as the answer for how well the medication work for him/her? } & $1=$ yes $\quad 0=$ no \\
\hline \multicolumn{3}{|l|}{ Did R name the prescribed drug as a drug that bothers him/her? } \\
\hline & & $1=$ yes $0=$ no \\
\hline \multicolumn{3}{|l|}{ Recall Screen } \\
\hline \multicolumn{2}{|l|}{ Did R receive a multiple dose regimen ( 2 or more times/day)? } & $1=$ yes $\quad 0=$ no \\
\hline \multicolumn{2}{|c|}{$\begin{array}{l}\text { Did R report "very hard" or "somewhat hard" in response to how hard is it for him/her to remember to take all } \\
\text { the pills? }\end{array}$} & $1=$ yes $\quad 0=$ no \\
\hline Access Screen & Somewhat hard & Not hard at all \\
\hline (score) & 1 & 0 \\
\hline \multicolumn{3}{|l|}{ Read the print on the bottle } \\
\hline \multicolumn{3}{|l|}{ Open or close the medicine bottle } \\
\hline \multicolumn{3}{|l|}{ Remember to take all the pills } \\
\hline \multicolumn{3}{|l|}{ Get your refills in time } \\
\hline Take so many pills at the same time & & \\
\hline
\end{tabular}

Note: Score of $\geq 1$ indicates positive screen for potential non adherence.

R- respondent/patient

study from the Institutional Ethics Committee of Bharati Medical College \& Research centre, Pune. Patient's informed consent was taken for the study. The patient details like age, gender, educational and employment status, physical activity, social history, past medical and medication history and current medications were noted in self pre designed patient pro forma. The medication adherence was assessed by using Brief Medication Questionnaire (BMQ) developed by Bonnie L. Svarstad. ${ }^{4}$ BMQ consists of four sub-scales (regimen, beliefs, recalls and access screens). The tool includes 5 -items regimen screen that asks patients how they took each medication in the past week, a 2-items belief screen that asks about drug effects and bothersome features, a 2-items recall screen about potential difficulties remembering and a 2 -item access screen which evaluates the patient difficulty in buying and re-filling their medications in time. Scoring for BMQ is according to the number of positive response. Factors associated with non adherence were determined by five sets of factors by WHO such as social and economic, health care system, condition-related, therapy-related and patient-related. The data gathered were analysed.

\section{RESULTS}

A total of 240 patients were enrolled after the consideration of the inclusion criteria. Table 1 indicates Socio demographic characteristics and health status of elderly patients in which total distribution of patients with respect to age group showed that the highest numbers of patients were observed in age group of 60-70 years (61.7\%). Out of 240 patients, $60 \%$ were male, $81.7 \%$ were married, $49.1 \%$ were unemployed, $15.8 \%$ patients were illiterates and $35.0 \%$ patients were having social habits. $92.5 \%$ patients were found to be having more than one disease and $62.5 \%$ patients were consumers of $4-6$ drugs per day.
Figure 1 lists the chronic diseases reported in elderly patients. The common conditions among elderly were cardiovascular diseases (11.67\%), endocrine disorders (5.83) and central nervous system disorder $(4.17 \%)$. The number of patients with diabetes and coexisting cardiovascular diseases was high (73.3\%).

Most of the elderly people have multiple medical conditions which require multiple medications for the proper management. Figure 2 represents the prescription pattern of drugs in elderly patients, which showed Anti hypertensives were the mostly prescribed drug (89.1\%), followed by Anti diabetics (83.3\%) and Anti hyperlipidemic drugs (65.0\%). The assessment of the patient's responses to the four scale Brief Medication Questionnaire showed that out of 240 patients, $94.1 \%$ patients had non adherence in regimen screen, $40.8 \%$ had non adherence in belief screen, $85.0 \%$ patients had non adherence in recall screen and $62.5 \%$ patients had non adherence in access screen (Figure 3).

Out of 240 patients, more than half of patients were unable to name their medications $(68.3 \%)$. The number of patients who reported that they missed their medications was high (54.1\%). Furthermore, $31.7 \%$ patients responded that they did not know how well their medications worked for them and the number of patients who said that their medications bothered them was less (7.5\%). Out of 240 patients, $20.0 \%$ reported that they had difficulty to get their refill in time and $28.3 \%$ reported that it was hard for them to read the print on the container. (Table 2).

A multitude of reasons contribute to medication non adherence in elderly patients. Table 3 summarise the factors affecting medication adherence in elderly patients which showed that out of 240 patients, more than half of the patients $(74.1 \%)$ reported that they have difficulty in their dosage regimen and $52.5 \%$ patients had long duration of treatment period. $13.3 \%$ have indicated that it was at least somewhat hard to pay for 


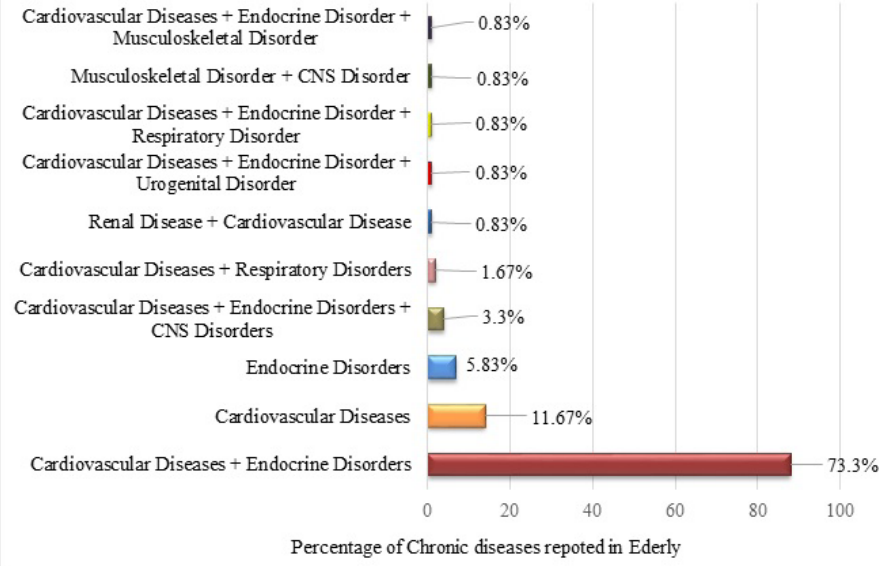

Figure 1: Chronic diseases reported in Elderly Patients.

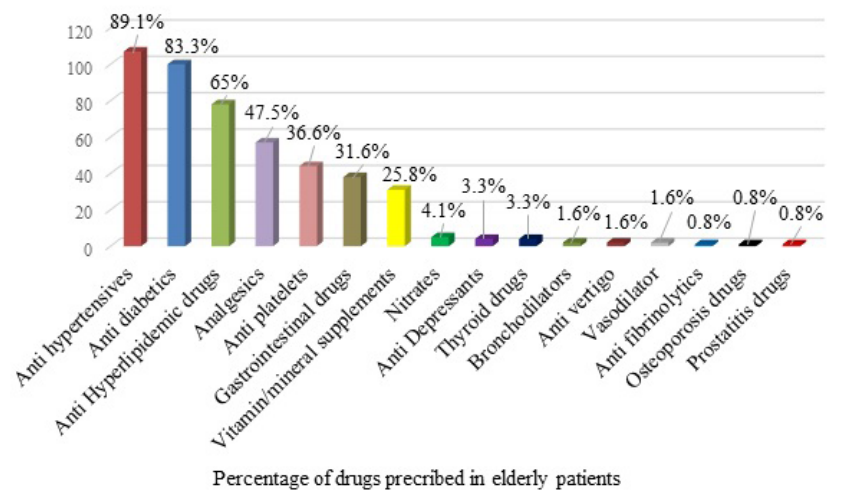

Figure 2: Prescription pattern of drugs in elderly patients.

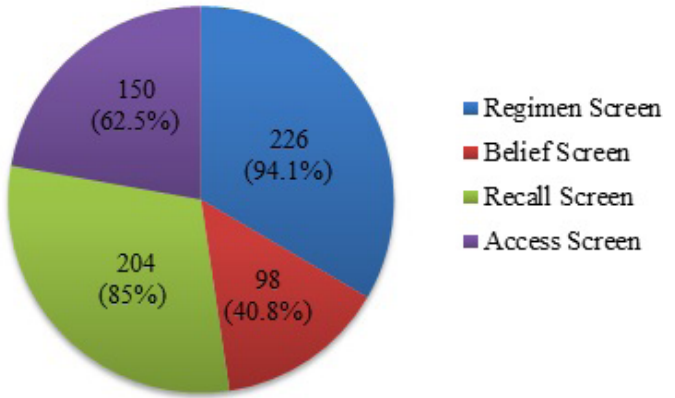

Percentage of patient responses to Brief Medication Questionnaire

Figure 3: Distribution of medication non adherence in elderly patients by BMQ scale.

their medications. The main reason for non adherence would be related to patient related factors such as lack of knowledge about the disease $(63.3 \%)$, inadequate knowledge regarding therapy (60.0\%), forgetfulness (50.84\%), being busy (22.5\%). 51.7\% patients reported that taking various medicines at the same time was inconvenient, Nearly half of the patients $(48.3 \%)$ have agreed that it was at least somewhat hard to remember all the medications.
Table 1: Socio demographic characteristics and health status of elderly patients

\begin{tabular}{|c|c|c|}
\hline Characteristics & Number of patients & Percentage (\%) \\
\hline \multicolumn{3}{|l|}{ Age (in years) } \\
\hline $60-65$ & 74 & 30.9 \\
\hline $65-70$ & 74 & 30.9 \\
\hline $70-75$ & 62 & 25.9 \\
\hline $75-80$ & 14 & 5.9 \\
\hline $80-85$ & 12 & 5.0 \\
\hline$>85$ & 4 & 1.7 \\
\hline \multicolumn{3}{|l|}{ Gender } \\
\hline Male & 144 & 60.0 \\
\hline Female & 96 & 40.0 \\
\hline \multicolumn{3}{|l|}{ Marital Status } \\
\hline Married & 196 & 81.7 \\
\hline Unmarried & 4 & 1.7 \\
\hline Widowed & 40 & 16.7 \\
\hline \multicolumn{3}{|l|}{ Education level } \\
\hline Illiterate & 38 & 15.8 \\
\hline Primary school & 16 & 6.6 \\
\hline High school & 42 & 17.5 \\
\hline Higher secondary school & 40 & 16.6 \\
\hline Graduate & 70 & 29.1 \\
\hline Post graduate & 34 & 14.1 \\
\hline \multicolumn{3}{|l|}{ Social Habits } \\
\hline Smokers & 6 & 2.5 \\
\hline Alcoholic & 44 & 18.3 \\
\hline Tobacco & 2 & 0.8 \\
\hline Alcohol + smoking & 16 & 6.6 \\
\hline Mishri & 16 & 6.6 \\
\hline No social habits & 156 & 65.0 \\
\hline \multicolumn{3}{|l|}{ Employment status } \\
\hline Retired & 102 & 42.5 \\
\hline Unemployed & 118 & 49.1 \\
\hline Business & 12 & 5.0 \\
\hline Employed & 8 & 3.3 \\
\hline \multicolumn{3}{|l|}{ Number of diseases } \\
\hline 1 & 18 & 7.5 \\
\hline 2 & 148 & 61.6 \\
\hline 3 & 62 & 25.8 \\
\hline 4 & 12 & 5.0 \\
\hline \multicolumn{3}{|l|}{ Number of drugs } \\
\hline $4-6$ & 150 & 62.5 \\
\hline $6-8$ & 60 & 25.0 \\
\hline $8-10$ & 18 & 7.5 \\
\hline$>10$ & 12 & 5.0 \\
\hline \multicolumn{3}{|c|}{ Frequency of use of medical services } \\
\hline Once in Six months & 98 & 40.8 \\
\hline Twice in Six months & 44 & 18.3 \\
\hline Once in a year & 90 & 37.5 \\
\hline Not keeping appointment time & 8 & 3.3 \\
\hline
\end{tabular}


Table 2: Description of the issues covered in the domains of BMQ

\begin{tabular}{|c|c|c|}
\hline Questions & $\begin{array}{l}\text { Number of } \\
\text { patients }\end{array}$ & $\begin{array}{c}\text { Percentage } \\
(\%)\end{array}$ \\
\hline \multicolumn{3}{|l|}{ Regimen screen } \\
\hline $\begin{array}{l}\text { Failed to list the prescribed drugs in the } \\
\text { initial report }\end{array}$ & 164 & 68.3 \\
\hline Reported missed days/dose of treatment & 130 & 54.1 \\
\hline $\begin{array}{l}\text { Reduce or cut down the prescribed } \\
\text { amount per dose }\end{array}$ & 28 & 11.6 \\
\hline \multicolumn{3}{|l|}{ Belief screen } \\
\hline $\begin{array}{l}\text { Reported the medication effectiveness "not } \\
\text { well" or "don't know" }\end{array}$ & 76 & 31.6 \\
\hline $\begin{array}{l}\text { Reported the medication has caused a } \\
\text { bothersome effect }\end{array}$ & 18 & 7.5 \\
\hline \multicolumn{3}{|l|}{ Recall screen } \\
\hline Received a multiple dose regimen & 178 & 74.1 \\
\hline $\begin{array}{l}\text { Reported difficulty in remembering to take } \\
\text { medications }\end{array}$ & 116 & 48.3 \\
\hline \multicolumn{3}{|l|}{ Access screen } \\
\hline $\begin{array}{l}\text { Reported difficulties in reading what was } \\
\text { written on the packet }\end{array}$ & 68 & 28.3 \\
\hline $\begin{array}{l}\text { Reported difficulty in obtaining the } \\
\text { medications on time }\end{array}$ & 48 & 20.0 \\
\hline $\begin{array}{l}\text { Reported difficulties in taking various } \\
\text { medicine at the same time }\end{array}$ & 124 & 51.7 \\
\hline
\end{tabular}

Table 3: Factors affecting medication adherence in elderly patients

\begin{tabular}{|c|c|c|c|}
\hline Sr.No: & Factors & $\begin{array}{l}\text { Number of } \\
\text { Patients }\end{array}$ & $\begin{array}{l}\text { Percentage } \\
\text { (\%) }\end{array}$ \\
\hline \multirow[t]{3}{*}{1} & SOCIAL AND ECONOMIC & & \\
\hline & Cost of medication too expensive & 32 & 13.3 \\
\hline & Illiterate & 38 & 15.8 \\
\hline \multirow[t]{5}{*}{2} & THERAPY RELATED & & \\
\hline & Complexity of medication regimen & 178 & 74.1 \\
\hline & $\begin{array}{l}\text { No of medications / too much } \\
\text { medications }\end{array}$ & 126 & 52.5 \\
\hline & Side effects & 18 & 7.5 \\
\hline & Long duration of treatment period & 126 & 52.5 \\
\hline \multirow[t]{12}{*}{3} & PATIENT RELATED & & \\
\hline & Lack of knowledge about the disease & 152 & 63.3 \\
\hline & $\begin{array}{l}\text { Inadequate knowledge regarding } \\
\text { therapy }\end{array}$ & 144 & 60.0 \\
\hline & Remember to take all the pills & 116 & 48.3 \\
\hline & Take so many pills at the same time & 124 & 51.7 \\
\hline & Difficulty on refilling in time & 48 & 20.0 \\
\hline & Forgetfulness & 86 & 35.8 \\
\hline & Being busy & 18 & 7.5 \\
\hline & Forgetfulness + Being busy & 36 & 15.0 \\
\hline & Decision to omit & 24 & 10.0 \\
\hline & When felt worse / bad & 28 & 11.7 \\
\hline & Alcohol & 60 & 25.0 \\
\hline
\end{tabular}

\section{DISCUSSION}

The geriatric population is on the rise worldwide. This population is vulnerable to many diseases and medication noncompliance. Medication non adherence lowers treatment effectiveness, and is thus a very important problem in the management of patients with chronic diseases requiring long term treatments. We undertook this study in order to understand the factors associated with low adherence to pharmacotherapy in elderly patients.

Age has an important influence on the incidence of diseases in elderly. In this study, highest incidence of chronic diseases occurred among those aged $60-70 y r s(61.7 \%)$. This was similar to another study conducted in Bangalore where most of the patients were in the age group of $65-70 \mathrm{yrs}$ $(79.24 \%){ }^{5}$ Males $(60 \%)$ were predominated in this study population, which was in agreement with the results of other studies conducted in India ${ }^{6}$ and United States. ${ }^{7}$ The reason for this might be smoking, alcoholic habits and other lifestyle changes that are seen more commonly in males and these factors have effect on health and chronic diseases. In the employment status, the unemployed patients had more prevalence with $49.17 \%$ than employed with $8.33 \%$ which was similar to other study. ${ }^{8}$ The number of patients having social habits in this study was 35\% which was similar to another study conducted in Israel. ${ }^{9}$ Majority of the study population were married and graduates.

In this study, a total of 954 drug formulations were prescribed to 240 patients for different diseases. 4-6 drugs were prescribed for most patients (62.5\%) followed by $>6$ drugs $(25 \%)$, whereas a study conducted ${ }^{5}$ reported that 5-8 drugs were prescribed for most patients (46.22\%) followed by $>8$ drugs $(42.45 \%)$. In our study, the number of patients with diabetes and coexisting cardiovascular diseases were high (73.33\%). This resembles to anot her study conducted. ${ }^{10}$ In this study, Anti hypertensives were the most commonly used prescription drugs (89.1\%). This was consistent with the findings reported. ${ }^{11,12}$ The use of Ant diabetics were high in this study (83.3\%) as compared to others who reported the use ranging $40 \% .^{13}$ A total of 111 (92.5\%) patients suffered from co-morbid conditions which were similar to another study conducted in pune. ${ }^{8,14}$

Adherence to medications have always been a problem among elderly patients. As elderly people are prone to multiple comorbidities, they are at higher risk of polypharmacy and therefore may present with higher risk of non adherence to medications compared to the younger population. Medication non-adherence lowers the effectiveness of treatments and raises medical costs. There are many different methods for assessing adherence to medications such as patient questionnaires, self-reports, pill counts, assessment of the patient's clinical response, measurement of physiological markers and patient diaries. Although many methods have been used in clinical practise to measure adherence, self-reports of the taken medication is the most reasonable, accurate and ideal to an Indian setup because it promotes a candid exchange between the treating clinician and the treated patient. ${ }^{15}$

In this study, medication adherence was assessed by Brief Medication Questionnaire (BMQ). ${ }^{4}$ It is more sensitive in identifying and diagnosing adherence problems. It consist of four subscales (regimen, belief, recall and access screens). The higher the score in each aspect indicates an increased potential for adherence problems whereas a negative screen indicates that there was decreased non adherence.

The analysis of Brief Medication Questionnaire showed that the patient were more adherent in Belief screen compared to other screens and most of the patients were non adherent in Regimen and Recall screens. The effect of medications depends on the efficacy and the patient adherence to the intended regimen. Adherence with medication regimens is essential for attaining maximal therapeutic benefits. ${ }^{16}$ In Regimen screen, the main factor for non adherence was missed dose of treatment (54.16\%). 
Roy et al:: Assessment of factors associated with low adherence to pharmacotherapy in elderly patients

In Recall screen, the two main obstacles reported by elderly patients were multiple dose regimen and difficulty in remembering to take medications which was found to be $74.16 \%$ and $48.33 \%$. These was similar to another study, "Factors associated with low adherence to medications in older adults" conducted. ${ }^{17}$

The adherence rate of $29.58 \%$ in this study was lower than adherence rate of $42.6 \%$ reported in another study conducted by AL-Hajje A et al. ${ }^{18}$ In a study conducted by Ahmed et $a l^{10}$, the number of patients who reported that they missed their medication was $76.3 \%$, the number of patients who had a concern or doubt when asked how well the medications worked for them was $54.3 \%$ and the number of patients who said that their medications have bothered them was $16 \%$, which were high compared to our study.

In this study, nearly half of the patients (48.3\%) have agreed that it was somewhat hard to remember all the medications, which was consistent with a previous study. ${ }^{19}$ Studies have shown that older adults skip doses, reduce doses or do not get prescriptions filled because they cannot afford to pay for medications. $13.3 \%$ have indicated that it was somewhat hard to pay for their medications, which complies with another study. ${ }^{20} 20 \%$ reported that they had difficulty to get their refill in time, however this was in contrast with a previous study. ${ }^{21}$ Our study confirmed that a complicated drug regimen is an important risk factor associated with drug non adherence which is because, more than half of the patients $(74.1 \%)$ had difficulty in their dosage regimen which was remarkably high.

Other patient related factors causing non adherence includes forgetfulness, nature of work and busy schedule. A study identified, forgetfulness (16.19\%) and being busy (13.33\%), as some of the reasons why some patients do not take their medications as prescribed, which when compared with our study was found to be more. ${ }^{8}$ The therapy related factor that influences medication adherence is multiple medications needed throughout the day (52.5\%). ${ }^{22}$ Also patients who did not have adequate knowledge about their medication regimen were more likely to be non adherent. ${ }^{23}$ Many patients consciously choose not to fill a prescription or not to take their medicines as prescribed. These choices are influenced by a number of factors related to patient's experiences, perceptions and understanding about their disease and can include perceptions about the nature and severity of their illness, denial of illness and the need to take medicines, the assumption that once the symptoms improve or when feel better, they can discontinue the use of medicines, fear of side effects.

\section{CONCLUSION}

In conclusion, our study reveals that most of the patients were non adherent to Regimen and Recall screens. Various factors of medication nonadherence were complexity of medication regimen, lack of knowledge about the disease and therapy, difficulty in remembering to take medications, taking so many pills at the same time, missed dose of treatment.

Based on our study, following recommendations could improve drug adherence among the elderly patients such as the physicians and pharmacists improving on the areas of patient education and medication counselling, prescriptions should be simplified as far as possible and among those who have difficulties with drug adherence, packing medication and the use of medication boxes could be helpful.

\section{ACKNOWLEDGEMENT}

We extend our immense thanks to Dr. Bonnie L. Svarstad, who granted us the permission to use BMQ scale that provided a good basis for our study. We also would like to thank to all the residents, post graduate students and nurses of Medicine Department, Bharati Hospital \& Research Centre, Bharati Vidyapeeth Deemed University, Pune, for helping us in the completion of the study.

\section{CONFLICT OF INTEREST}

No conflict of interest are declared.

\section{REFERENCES}

1. Kocurek B. Promoting medication adherence in older adults and the rest of us. Diabetes Spectr. 2009;22(2):80-4

2. Saleem F, Hassali M, Shafie A, Atif M. Drug Attitude and Adherence: A Qualitative Insight of Patients with Hypertension. J Young Pharm. 2012;4(2):101-7.

3. Ramanath KV, Balaji DBSS, Nagakishore $\mathrm{CH}$, Mahesh KS, Bhanuprakash M. A Study on Impact of Clinical Pharmacist Interventions on Medication Adherence and Quality of Life in Rural Hypertensive Patients. JYoung Pharm. 2012;4(2):95-100.

4. Svarstad B, Chewning B, Sleath B, Claesson C. The brief medication questionnaire: A tool for screening patient adherence and barriers to adherence. Patient Educ Couns. 1999;37(2):113-24.

5. Veena D.R, Padma L, Sapna Patil. Drug prescribing pattern in elderly patients in a teaching hospital. IOSR Journal of Dental and Medical Sciences (JDMS) 2012;1(5):39-42.

6. Vengurlekar S, Shukla P, Patidar P, Bafna R, Jain S. Prescribing pattern of ant diabetic drugs in Indore city hospital. Indian J Pharm Sci. 2008;70(5):637.

7. Willey CJ, Andrade SE, Cohen J, Fuller JC, Gurwitz JH. Polypharmacy with oral antidiabetic agents: An indicator of poor glycemic control. Am J Manag Care. 2006;12(8):435-40.

8. Sajith M, Pankaj M, Pawar A, Modi A, Sumariya R. Medication adherence to Anti diabetic therapy in patients with type 2 Diabetes Mellitus. Int J Pharm Pharm Sci. 2014;6:564-70.

9. Fuchs Z, Novikov I, Blumstein T, Chetrit A, Gindin J, Modan B. Patterns of drug use among the community-dwelling old-old population in Israel. Isr Med Assoc J. 2003;5(5):346-51.

10. Ahmed A Elnour A Yousif M, Farah F Osman H Abasaeed A Improving Adher ence to Prescribed Anti diabetics and Cardiovascular Medications in Primary Health Care Centres in Nyala City, South Darfur State-Sudan. Pharmacol Pharm. 2013;4(9):701-9

11. Woo J, Ho S, Yuen Y, Lau J. Drug Use in an Elderly Chinese Population: Prevalence and Associated Factors. Gerontology. 1995;41(2):98-108.

12. Stewart R, Moore M, May F Marks R. Hale W. A longitudinal evaluation of drug use in an ambulatory elderly population. J Clin Epidemiol. 1991;44(12):1353-9.

13. Hor J. Prescription Drug Use Among Elderly Admitted to Medical Wards in a Malaysian Government Hospital. Med J Malaysia. 2008:63(2):125-30.

14. Natarajan N, Putnam W, Aarsen K, Lawson K, Burge F. Adherence to antihypertensive medications among family practise patients with diabetes mellitus and hypertension. Can Fam Physician. 2013;59(2):93-100.

15. Rajesh R, Sonika S, Sudha V, Varma D. Association between Medication Adherence Outcomes and Adverse Drug Reactions to Highly Active Antiretroviral Therapy in Indian Human Immunodeficiency Virus-Positive Patients. J Young Pharm. 2012;4(4):250-60.

16. Shamkuwar C, Kumari N, Meshram S, Dakhale G, Motghare V. Evaluation of Knowledge, Attitude and Medication Adherence among Asthmatics Outpatients in Tertiary Care Teaching Hospital-A Questionnaire Based Study. J Young Pharm. 2015;8(1):39-43

17. Tavares N, Bertoldi A, Facchini L, Franca G, Mengue S. Factors associated with low adherence to medications in older adults. Rev Saude Publica. 2013;47(6):1092-101.

18. Al-Hajje A, Awada S, Rachidi S, Zein S, Bawab W, El-Hajj Z et al. Factors affecting medication adherence in Lebanese patients with chronic diseases. Pharm Pract (Granada). 2015;13(3):590

19. Sathwik B, Narahari M, Gurudev K, Parthasarathi G. Impact of Clinical Pharmacist-Provided Education on Medication Adherence Behaviour in ESRD Patients on Haemodialysis. IJPS. 2009;5(1):21-30.

20. Friedman D, Hahn S, Gelb L, Tan J, Shah S, Kim E et al. Doctor-Patient Communication, Health-Related Beliefs and Adherence in Glaucoma Results from the Glaucoma Adherence and Persistency Study. Ophthalmology. 2008:115(8):1320-7.

21. Krass I, Taylor S, Smith C, Armour C. Impact on Medication Use and Adherence of Australian Pharmacists' Diabetes Care Services. J Am Pharm Assoc (2003) 2005:45(1):33-40.

22. Wu JR, Moser DK, Lennie TA, Peden AR, Chen YC, Heo S. Factors influencing medication adherence in patients with heart failure. Heart Lung. 2008;37(1):8-16

23. Hope C, Wu J, Tu W Young J, Murray M. Association of medication adherence, knowledge and skills with emergency department visits by adults 50 years or older with congestive heart failure. Am J Health Syst Pharm. 2004;61(19):2043-9. 